\title{
Point of care echocardiography and lung ultrasound in critically ill patients with COVID-19
}

\author{
Martin Altersberger - Matthias Schneider - Martina Schiller • Christina Binder-Rodriguez - Martin Genger • \\ Mounir Khafaga · Thomas Binder · Helmut Prosch
}

Received: 21 December 2020 / Accepted: 25 August 2021 / Published online: 29 October 2021

(C) The Author(s) 2021

Summary Hundreds of millions got infected, and millions have died worldwide and still the number of cases is rising.

Chest radiographs and computed tomography (CT) are useful for imaging the lung but their use in infectious diseases is limited due to hygiene and availability.

Lung ultrasound has been shown to be useful in the context of the pandemic, providing clinicians with valuable insights and helping identify complications such as pleural effusion in heart failure or bacterial superinfections. Moreover, lung ultrasound is useful

Video online The online version of this article contains 4 videos. The article and the videos are available online (https://doi.org/10.1007/s00508-021-01968-y). The videos can be found in the article back matter as "Electronic Supplementary Material".

M. Altersberger $\cdot$ M. Khafaga

Rehabilitation Center Hochegg for Cardiovascular

and Respiratory Diseases, Friedrich Hillegeist

Straße 2, 2840 Grimmenstein, Austria

martin.altersberger.90@gmail.com

M. Altersberger $\cdot$ M. Genger

Department of Cardiology, Nephrology and Intensive Care

Medicine, State Hospital Steyr, Steyr, Austria

M. Schneider · C. Binder-Rodriguez · T. Binder $(\bowtie)$

Department of Internal Medicine II, Division of

Cardiology, Medical University of Vienna, Waehringer

Guertel 18-20, 1090 Vienna, Austria

thomas.binder@meduniwien.ac.at

M. Schiller

Department of Radiology, State hospital Neunkirchen,

Neunkirchen, Austria

H. Prosch

Department of Biomedical Imaging and Image-guided Therapy, Medical University of Vienna, Vienna, Austria for identifying possible complications of procedures, in particular, pneumothorax.

Associations between coronavirus disease 2019 (COVID-19) and cardiac complications, such as acute myocardial infarction and myocarditis, have been reported. As such, point of care echocardiography as well as a comprehensive approach in later stages of the disease provide important information for optimally diagnosing and treating complications of COVID-19.

In our experience, lung ultrasound in combination with echocardiography, has a great impact on treatment decisions. In the acute state as well as in the follow-up setting after a severe or critical state of COVID19 , ultrasound can be of great impact to monitor the progression and regression of disease.

Keywords COVID-19 • Lung ultrasound . Echocardiography $\cdot$ Point-of-care $\cdot$ POCUS

$\begin{array}{ll}\begin{array}{l}\text { Abbreviations } \\ \text { 4-ChV }\end{array} & \begin{array}{l}\text { Apical 4-chamber-view } \\ \text { ACS }\end{array} \\ \text { ad-RDT } & \begin{array}{l}\text { Antigen-detecting rapid diagnostic } \\ \text { tests }\end{array} \\ \text { AMI } & \text { Acute myocardial injury } \\ \text { ARDS } & \text { Acute respiratory distress syndrome } \\ \text { GLS } & \text { Global longitudinal strain } \\ \text { ICU } & \text { Intensive care unit } \\ \text { IVC } & \text { Inferior vena cava } \\ \text { LUS } & \text { Lung ultrasound } \\ \text { LV } & \text { Left ventricle } \\ \text { LVF } & \text { Left ventricular function } \\ \text { PE } & \text { Pulmonary embolism } \\ \text { PLAX } & \text { Parasternal long axis view } \\ \text { POCUS } & \text { Point of care ultrasound } \\ \text { RT-PCR } & \text { Real-time polymerase chain reac- } \\ & \text { tion }\end{array}$




$\begin{array}{ll}\text { RV } & \text { Right ventricle } \\ \text { RVF } & \text { Right ventricular function } \\ \text { sPAP } & \text { Systolic pulmonary artery pressure } \\ \text { Subcostal 4-ChV } & \text { Subcostal 4-chamber view } \\ \text { TAPSE } & \begin{array}{l}\text { Tricuspid annular plane systolic ex- } \\ \text { cursion }\end{array} \\ \text { TR } & \text { Tricuspid regurgitation } \\ \text { WMA } & \text { Wall motion abnormalities }\end{array}$

\section{Introduction}

At the end of December 2019, a novel coronavirus (SARS-CoV-2) began to spread in the city of Wuhan, Hubei Province, China $[1,2]$. Now, at the time of writing, the whole world is being held hostage by what has become a global pandemic, and a true burden for healthcare professionals [3]. As of August 2021, almost 205 million cases have been reported worldwide and this number might be underestimated [4-10].

\section{Clinical presentation and diagnosis of COVID-19}

Patients with COVID-19 frequently present with fever and cough but a loss of taste and smell has also been reported $[11,12]$. Of COVID-19 positive cases $81 \%$ lead to a mild disease, whilst $14 \%$ of diagnosed patients become severely ill (requiring hospitalization) and 5\% become critically ill [11]. Patients presenting with hypoxia, Glasgow coma scale $<15$, and a breathing rate $>30 / \mathrm{min}$, have a higher mortality rate and should be admitted to hospital [13]. Patients who become critically ill due to acute respiratory failure or acute respiratory distress syndrome (ARDS) need to be treated in an intensive care unit (ICU). Furthermore, bacterial superinfection, cardiac complications, such as arrhythmia or acute myocardial injury (AMI) and iatrogenic complications (pneumothorax), also have to be combatted in an intensive care setting [11, 14-16].

Diagnosing COVID-19 can be challenging. At the beginning of the pandemic, the real-time polymerase chain reaction (RT-PCR) had not been validated. Therefore, false negatives occurred due to inadequate diagnostic timing [17]. Overall, combining molecular diagnostics with thorough clinical examinations and imaging can reduce the risk of false negatives, and allow efficient management in the context of this pandemic [18].

\section{Role of imaging}

Imaging plays a central role for the diagnosis, differential diagnosis and the detection of complications in many diseases. In the context of highly contagious diseases like COVID-19, the potential benefits of imaging have to be balanced against the risk of spreading the infection by exposing personnel during the examination. Consequently, a number of scientific societies have released guidelines on the use of imaging in
COVID-19 [19, 20]. Imaging should not be performed in asymptomatic patients or patients with only mild symptoms and should be restricted to patients with moderate to severe symptoms [19]. For the duration of the pandemic and up to the present day, nasopharyngeal RT-PCR testing has been the gold standard for diagnosing COVID-19 infections [10]. The sensitivity of this test is variable, with reported sensitivities ranging from $50 \%$ to $98 \%$; however, with optimal patient selection a high sensitivity and specificity can be obtained [18, 21]. Antigen-detecting rapid diagnostic tests (ad-RDT) are easy to use, are less costly than RT-PCR testing and, at 10-30 min, take less time to process but they also have a lower sensitivity. The specificity of ad-RDT tests is reported to be high, at $>97 \%$. Ad-RDT testing by trained personnel is recommended as a screening tool to minimize RT-PCR testing, 5-7 days after the onset of symptoms [22].

Point of care ultrasound (POCUS) has been proposed for use as a bed-side imaging modality for outpatient COVID-19 triage [23, 24]. Furthermore, POCUS has been recommended for follow-up care of COVID-19 patients in the ICU, and to identify cardiac pathologies such as myocarditis, acute coronary syndrome (ACS), pulmonary embolism and cardiac tamponade [25-29]. POCUS in the ICU should be performed whenever there is a need to answer a clinical question; for example, when trying to identify the cause for a decline in the respiratory condition of a patient. Overall, the use of POCUS and the advantages thereof need to be a balanced with the workload in the ICU, and the risks of disturbing patients' positions, especially in hemodynamically unstable patients [30].

Here, we present an ultrasound assessment protocol that can be used on COVID-19 patients who are critically or severely ill. Additionally, it is recommended that this protocol is undertaken at follow-up examinations after COVID-19 infections. Given the growing number of handheld devices and a broad use of POCUS [23], we provide images and ultrasound loops taken with both handheld devices as well as high-end machines.

\section{Lung ultrasound in COVID-19}

\section{Preset and settings}

There are important factors to be considered with respect to the presets and settings of devices used for lung ultrasound (LUS). In order to be able to detect ultrasound artifacts associated with COVID-19 pneumonia, a specific lung preset with a low mechanical index, single-focal point modality and no harmonic imaging or any other cosmetic filters should be chosen [27]. The focal zone should be placed at the pleural line. 

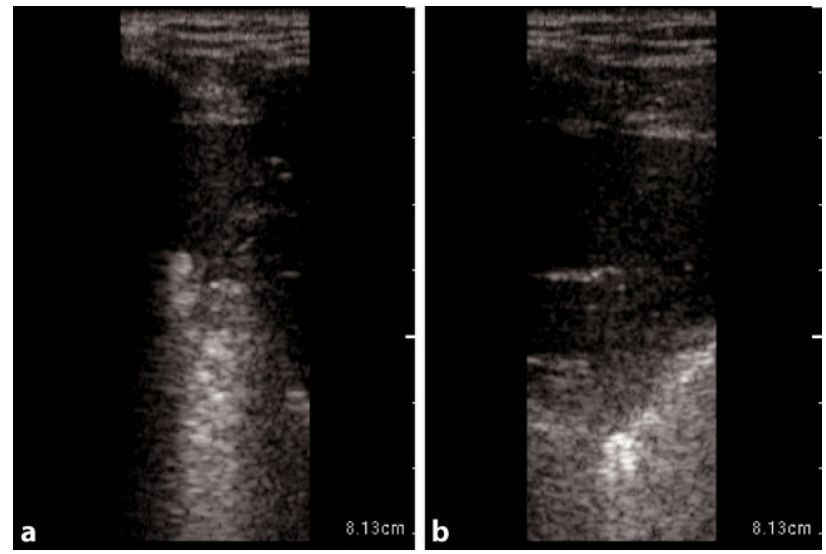

Fig. 1 Large anterior consolidation of the lung in POCUS in a longitudinal plane on the right anterior hemithorax in critical COVID-19. $\mathbf{a}$ and $\mathbf{b}$ stays the same as the intro provides the information needed in both images

\section{COVID-19 pneumonia}

In COVID-19 patients, a linear transducer should be used for scanning the anterior and posterior regions of the chest (at a depth setting of $6-8 \mathrm{~cm}$ ). Alternatively, a convex transducer can be used, and is particularly useful for scanning obese patients and the lateral or posterior regions of supine patients [23].

Typical LUS findings in patients with COVID19 pneumonia are bilateral areas of fragmentation and irregularities of the pleural line, sometimes with massive reverberation artifacts (recently named light beam appearance), small subpleural consolidations, and a reduction or absence of pleural sliding [24]. Reverberation artifacts arising from a fragmented pleural line are indicative of diffuse alveolar damage, diffuse parenchymatous lung diseases, or inflammatory diseases such as COVID-19 [28]. As the disease progresses, consolidations can be seen (Fig. 1). Small consolidations and subpleural consolidations are typical, yet not specific to COVID-19 [26]. As seen on ultrasound images, consolidations can be described as hypoechoic areas with small hyperechoic structures within (bronchograms), in combination with a tissue-like appearance or hepatization of the lungs [31, 32]. If there is a consolidation of an entire lobe, the borders will be well defined, whereas in smaller consolidations, the deeper borders appear irregular, described as the shred sign [33]. As lung ultrasound may help to predict the clinical course and outcomes of patients with COVID-19, and for follow-up purposes, the authors recommend a quantification of

Table 1 Suggested measurements-size quantification of consolidation

\begin{tabular}{|l|l|}
\hline Consolidation & \\
\hline Small & $0.5 \leq 2 \mathrm{~cm}$ \\
\hline Moderate & $2 \leq 5 \mathrm{~cm}$ \\
\hline Large & $>5 \mathrm{~cm}$ \\
\hline
\end{tabular}

Fragmented/irregular pleural line

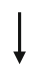

Reverberation artifacts (comet tails)

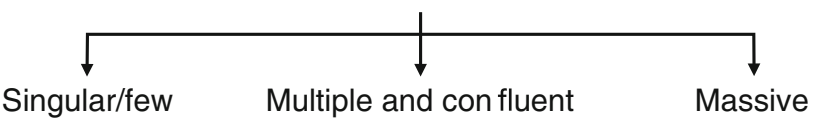

Fig. 2 Suggested quantification for reverberation artifacts (comet tails) in COVID-19

reverberation artifacts (Fig. 2), and suspected areas of consolidation (Figs. 1 and 3; Table 1; [24, 34]).

Dynamic air bronchograms (hyperechoic artifacts moving with the respiratory cycle) are observed within areas of consolidation. Fluid bronchograms (bronchi filled with anechoic fluid within areas of consolidation) present frequently as well. Consolidations can involve entire lobes or whole lungs [24, 35]. Doppler can be used to identify vascularization in consolidations, which is an additional indicator of pneumonia: a tree-like appearance of vessels in color Doppler and a predominately triphasic flow signal in pulsed wave Doppler, can be used to identify pulmonary arteries in consolidations. Monophasic blood flow is found in bronchial arteries. This can be help detect complications such as necrosis, by visualizing hypoechoic areas with no blood flow [36, 37].

Overall, pleural effusions in the context of bacterial superinfections tend to be small and localized in patients with COVID-19 [28]. If large pleural effusions are present, other differential diagnoses, such as heart failure (in particular right ventricular failure), kidney failure, and liver cirrhosis, have to be considered (Fig. 4b; [38]).

A pneumonia diagnosis, however, should never be made solely by imaging, but by interpreting the overall clinical status and the history of the patient, as well as laboratory parameters [35].

As COVID-19 pneumonia is characterized by a patchy distribution of affected lung parenchyma, areas with a normal appearance in LUS are seen next to pathological areas (Figs. 5a, 6 and 7; [24]). Due to the patchy distribution, a thorough examination is recommended, yet there is no validated scanning scheme [23]. We recommend a 12-zone scanning protocol, as it is, in our experience, simple to apply, reproducible, and easy to learn (Fig. 8). Beginning with zone one with a longitudinal view, followed by a transverse view, a scan of all intercostal spaces should be performed. Whenever possible, scanning of the posterior regions should be included for patients in a supine position, although this may not always be feasible. In this case, it is recommended to consider scanning the posterior regions during prone positioning [23]. 


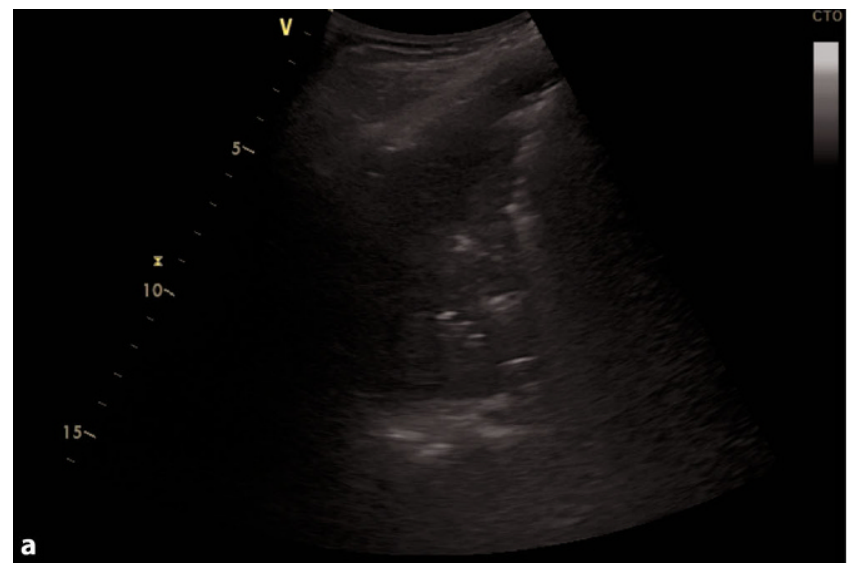

Fig. 3 Bacterial superinfection of the left lower lung lobe in COVID-19. a Large consolidation with air bronchograms in a bacterial superinfection in COVID-19. b Same consolidation

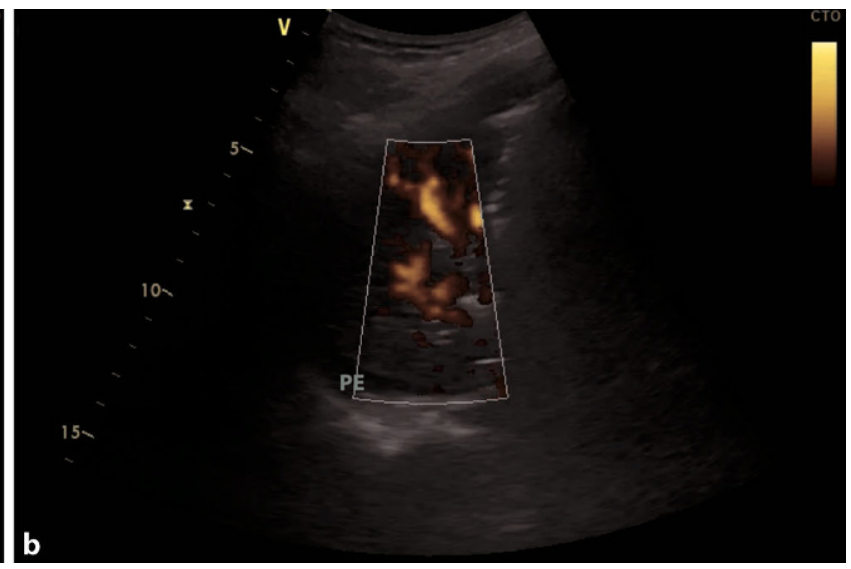

with power Doppler to display vascularization, a small pleural effusion is seen $(P E)$

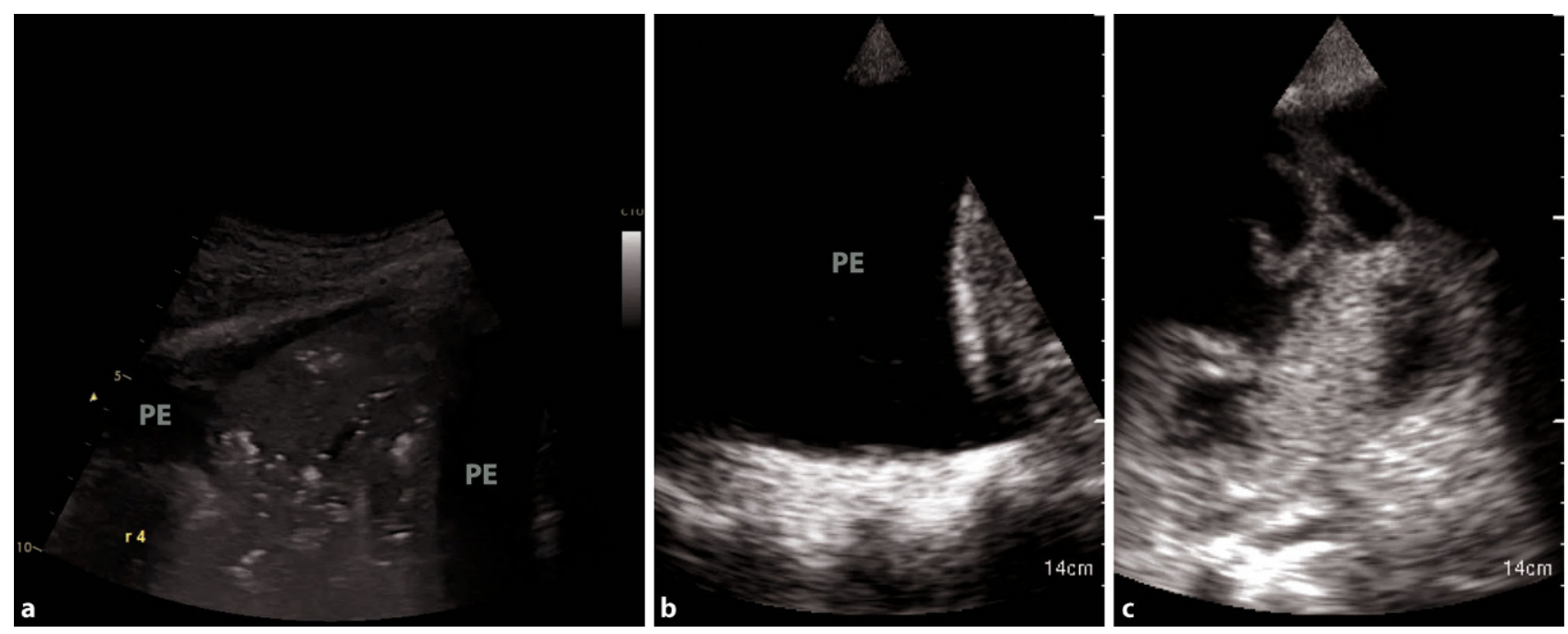

Fig. 4 Different types of pleural effusion. a Consolidation with tissue-like appearance in pneumonia. PE pleural effusion. b Large, uncomplicated pleural effusion in heart failure. c Complicated pleural effusion, empyema

Fig. 5 COVID-19 typical artifacts. a Fragmented pleural line with comet tail artifacts. b Fragmented pleural line with many comet tail artifacts
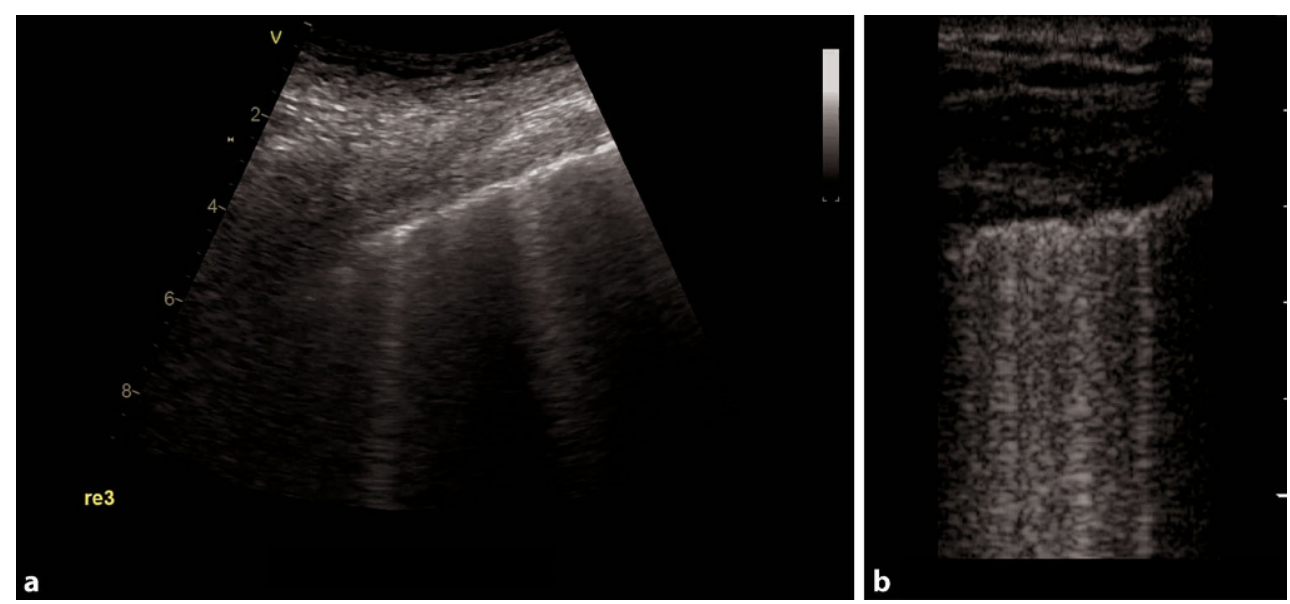

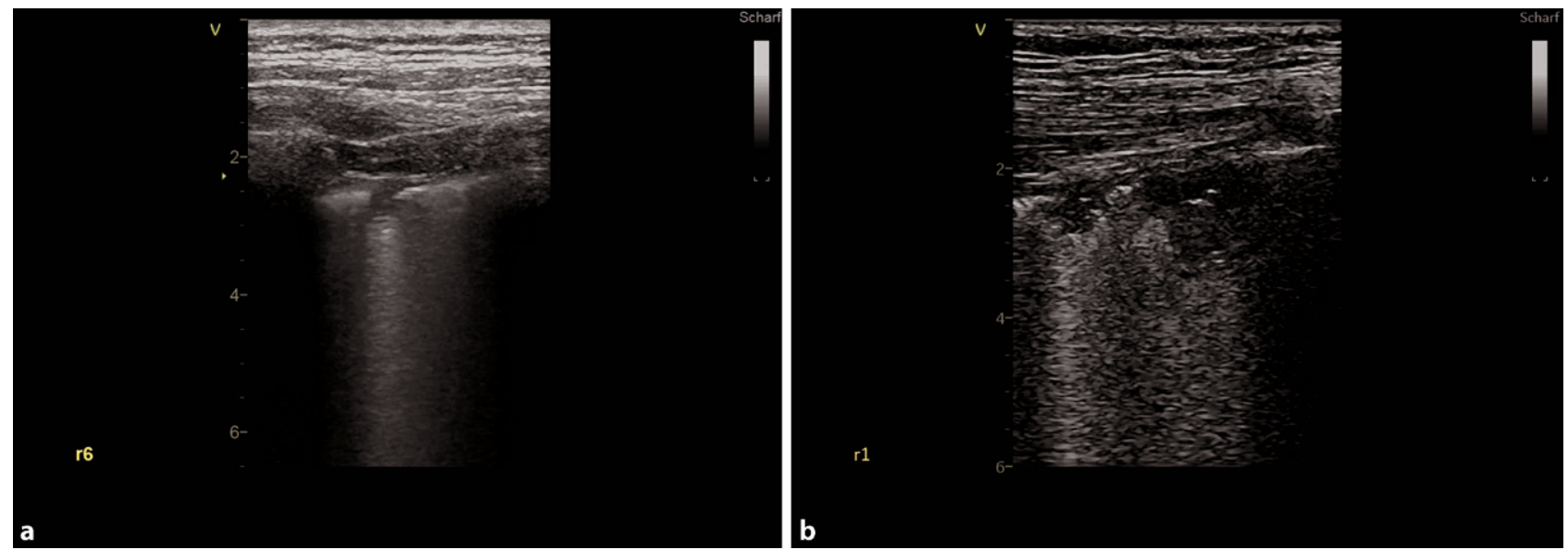

Fig. 6 Small consolidations in COVID-19. a Small consolidation with comet tail artifact in zone 6, right hemithorax. b Two small consolidations in zone 1 , right hemithorax

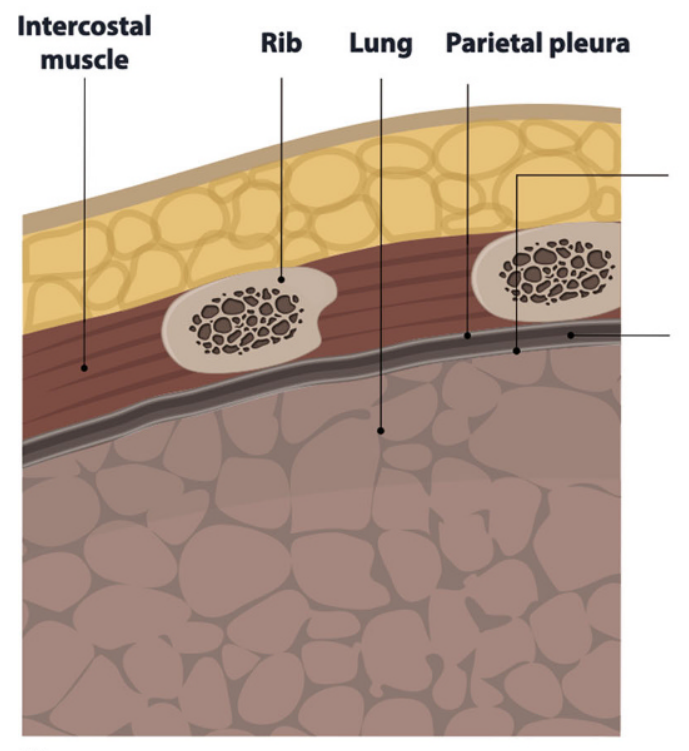

a

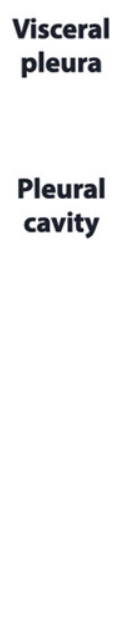

Fig. 7 Anatomy and sonoanatomy of the lung. a Anatomy of the lung in a longitudinal view. $\mathbf{b}$ Normal sonographic anatomy in a patient after a severe COVID-19 infection

\section{Diagnosis of pulmonary complications}

POCUS has been demonstrated to be a valuable tool to diagnose complications of COVID-19, such as pneumothorax or pleural effusions, or to confirm the suspected complications such as bacterial superinfections (Fig. 4a, c).

Pleural effusions are reportedly rare in COVID-19 pneumonia, and thus indicate a bacterial superinfection or heart failure [26]. To detect pleural effusions in supine patients, e.g. in an ICU, we recommend scanning the posterior regions with a convex or cardiac transducer as posterior as possible (Figs. 9 and 10). In an upright patient, the posterior regions-zone

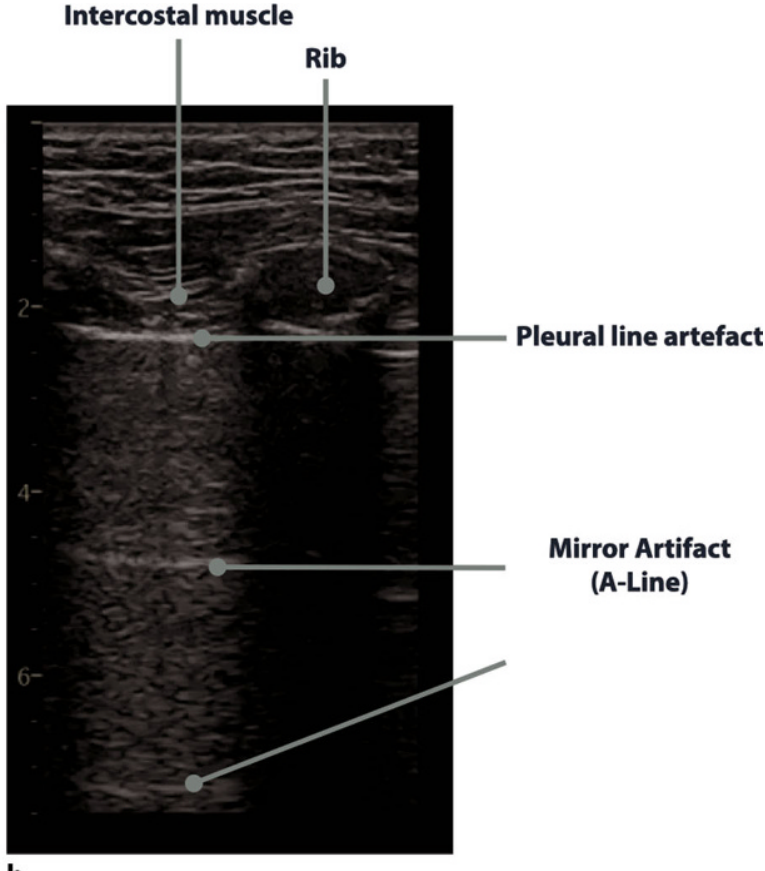

b 

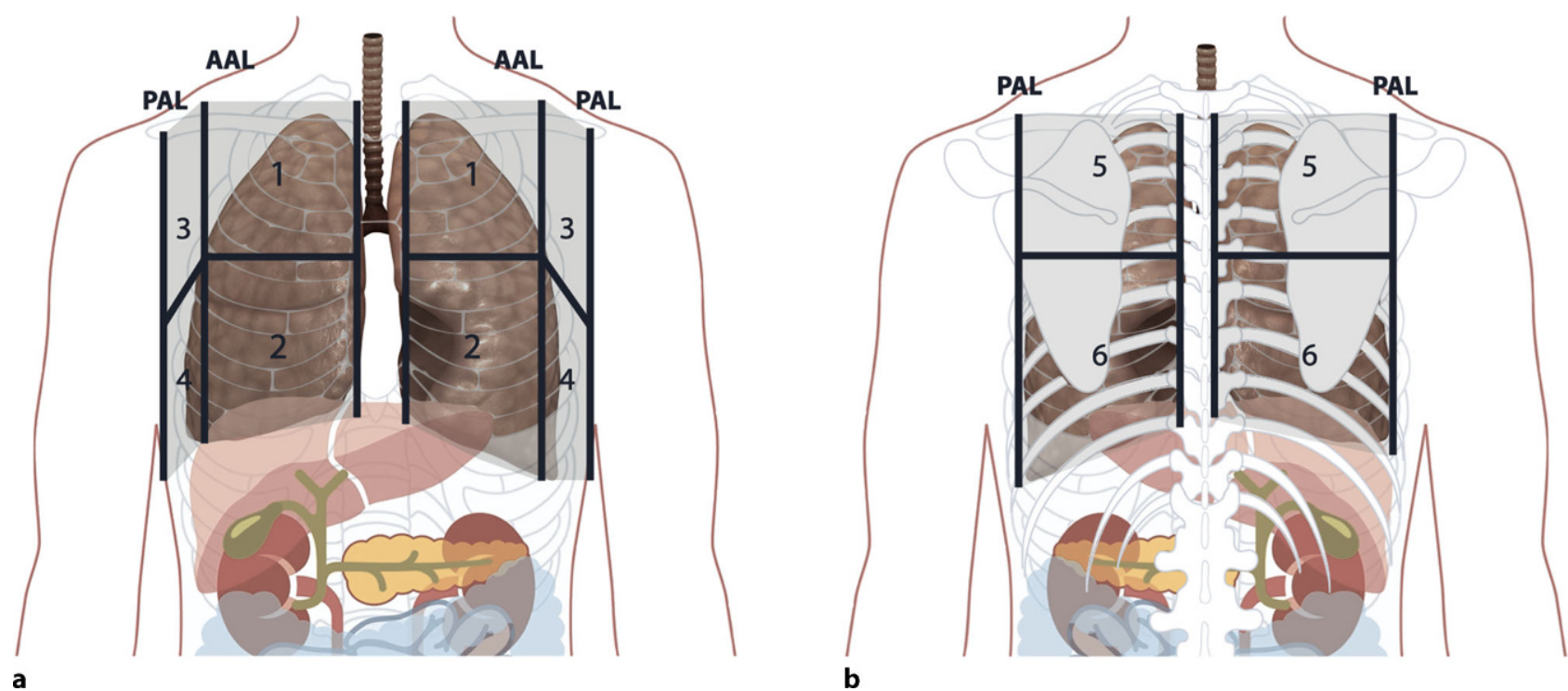

Fig. 8 Anatomical landmarks and scanning zones of lung ultrasound. a Anterior scanning zones of the chest. $A A L$ anterior axillary line, $P A L$ posterior axially line. b Posterior scanning zones of the chest
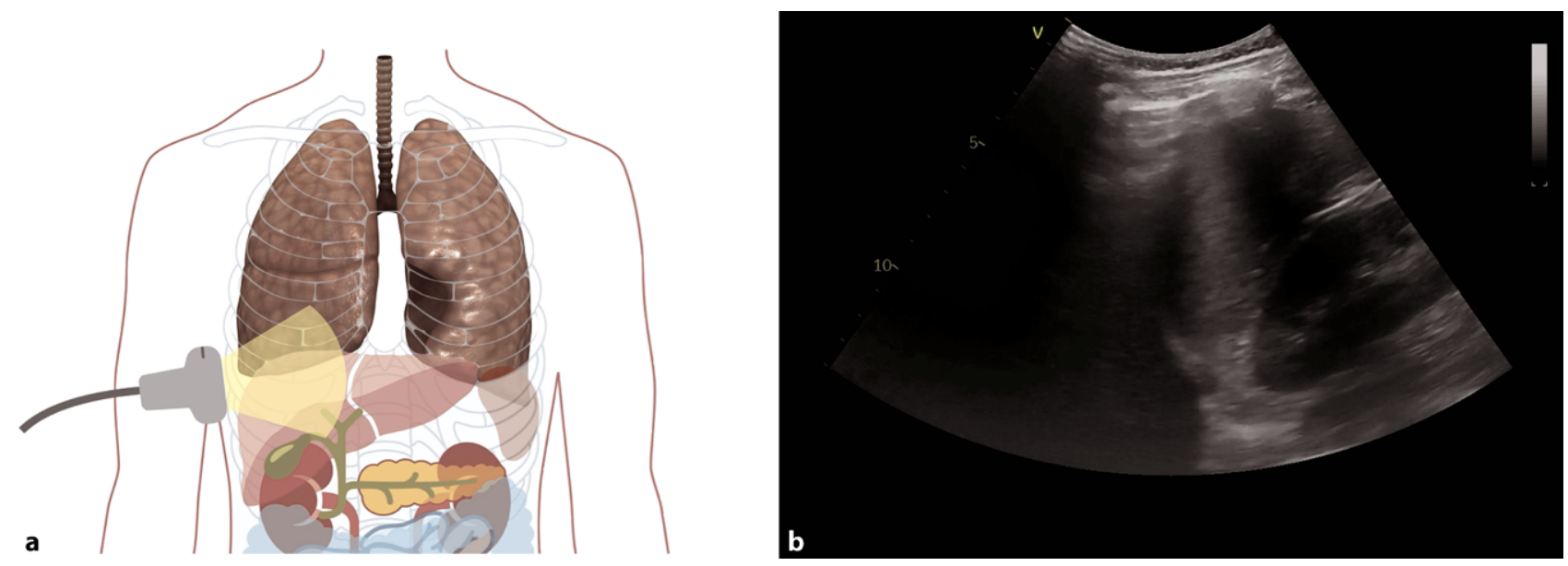

Fig. 9 Evaluation for pleural effusion-right hemithorax. a Schematic of the right sided approach. b Normal sonographic anatomy without pleural effusion
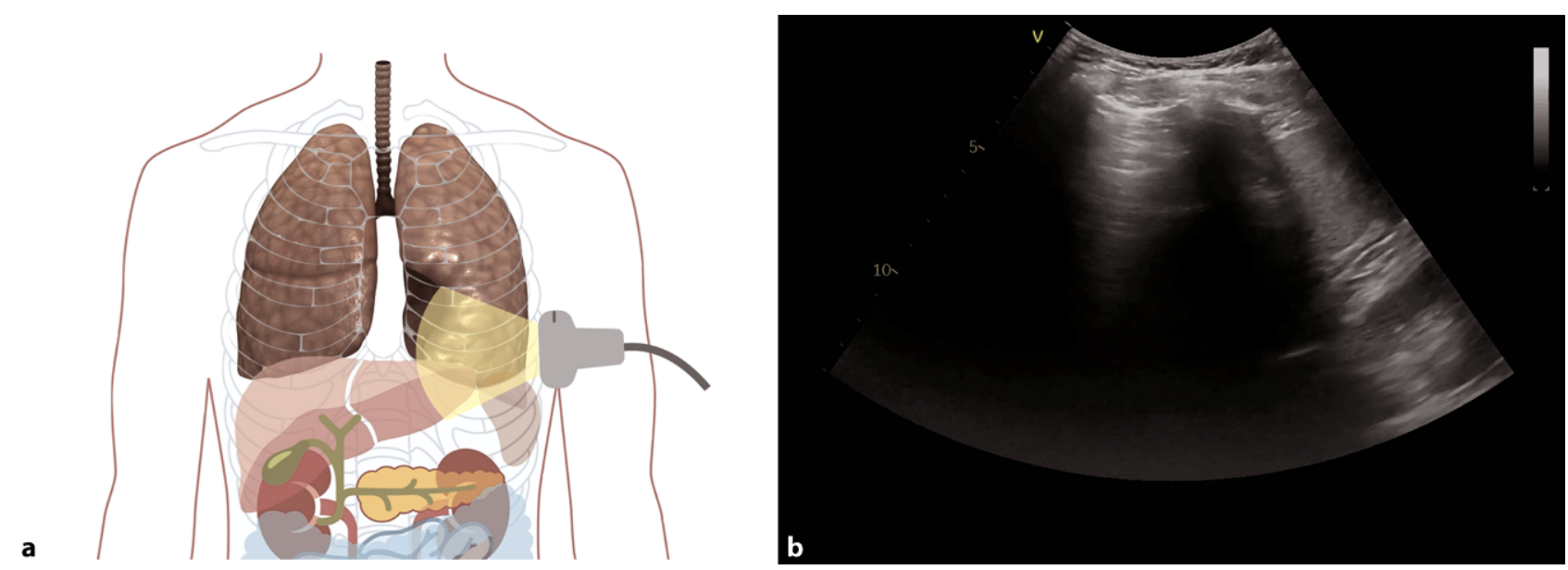

Fig. 10 Evaluation for pleural effusion-left hemithorax. a Schematic of the left-sided approach. b Normal sonographic anatomy without pleural effusion 
Patients who are critically ill often need to undergo procedures, for many of which a pneumothorax is a potential complication $[15,16]$. In COVID-19, there are also cases with spontaneous pneumothorax described, making this entity an important differential diagnosis of acute respiratory distress [41]. In ultrasound, an easy protocol for detecting a pneumothorax can be applied [40]. Scanning should start at the highest point of the thorax, identifying whether lung sliding is present. Lung sliding corresponds to the motion of the parietal and visceral pleura. In a pneumothorax, there is gas between the parietal and visceral pleura, and pleural sliding is lost. The presence of pleural sliding rules out a pneumothorax [32]. In cases where there is an absence of lung sliding but a presence of vertical reverberation artifacts (B-lines, comet tails), a pneumothorax can be ruled out as well, as there has to be a connection between the parietal
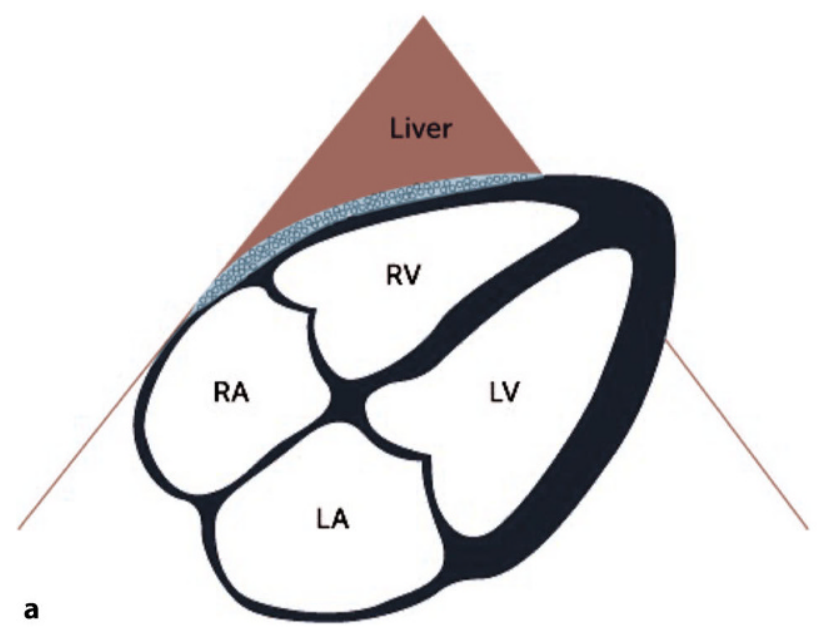

and visceral pleura to create such artifacts [32]. The presence of a lung pulse (a movement of the pleural line which is synchronous with the cardiac rhythm) rules out pneumothorax as well [42]. The most reliable rule in diagnosing a pneumothorax is the socalled lung point sign-the transition zone between the pneumothorax and the aerated lung (sliding on one side of the screen lung can be identified, whilst on the other, no lung sliding is present, video 2-lung point sign) [40]. It is recommended to use a point of care approach, performing a scan of the most anterior region (mostly in between zones 1 and 2) in a supine positioned patient [40].

\section{Indications - cardiac ultrasound}

In cardiac ultrasound, standard protocols exist, which should be followed in a comprehensive examination.

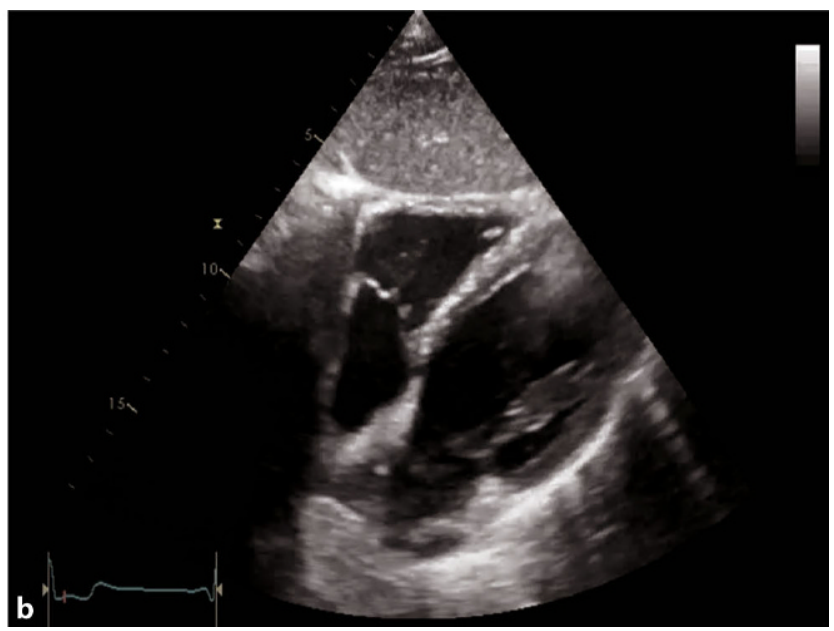

Fig. 11 Subcostal 4-chamber view (4-ChV). a Schematic of a subcostal 4-ChV. $R V$ right ventricle, $R A$ right atrium, $L V$ left ventricle, $L A$ left atrium. b 2D image of a subcostal $4-C h V$

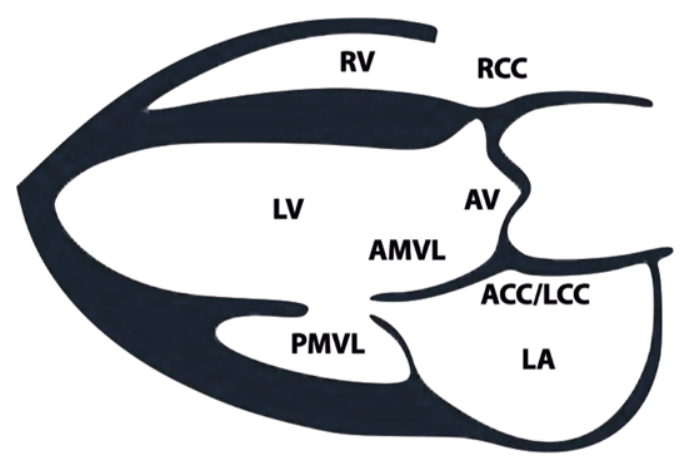

a

Fig. 12 Parasternal long axis view (PLAX). a PLAX-left ventricle $=L V$. $A M V L$ anterior mitral valve leaflet, $P M V L$ posterior MVL, $A V$ aortic valve, $R C C$ right coronary cusp,

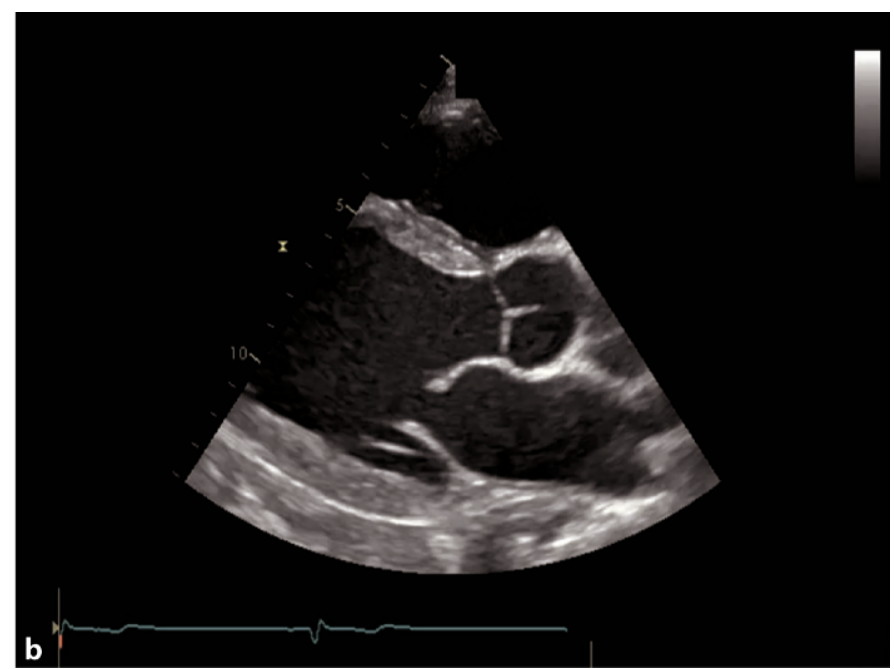

$A C C / L C C$ non-coronary/left coronary cusp, $R V$ right ventricle, $L A$ left atrium. $\mathbf{b} 2 \mathrm{D}$ image of a PLAX view 


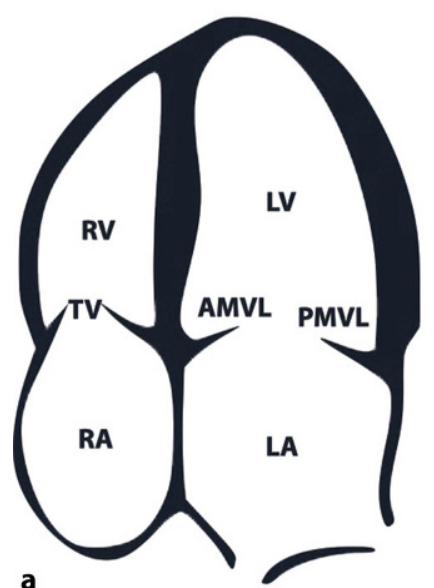

Fig. 13 Apical 4-chamber view (4-ChV). a Schematic of a 4-ChV. RV right ventricle, TV tricuspid valve, $R A$ right atrium, $L V$ left ventricle, $L A$ left atrium, $A M V L$ anterior mitral valve leaflet, $P M V L$ posterior mitral valve leaflet. $\mathbf{b} 2 \mathrm{D}$ image of an apical $4-C h V$

In a POCUS setting, the aim of the examination is to visualize the heart and to detect specific pathologies such as a pericardial effusion, tamponade, severely reduced left and right ventricular functions, or hypovolemia. Decisions may need to be made as to whether a referral to a comprehensive cardiac ultrasound examination or for other tests is indicated [29, 43].

In COVID-19, echocardiography is useful to evaluate the heart for myocarditis, myocardial injury, acute coronary syndromes and pulmonary embolism [44, 45].

A comprehensive examination can be achieved with various views; however, in acute and intensive care settings, a subcostal 4-chamber view (subcostal 4-ChV) should be utilized as it provides a lot of information and is easiest to achieve in a supine patient as well. If imaging from a subcostal approach is not possible, alternative views can be chosen, such as a parasternal long axis view (PLAX) or an apical 4-chamber view (4-ChV) (Figs. 11, 12 and 13).

\section{Myocardial injury and perimyocarditis/ myopericarditis}

Patients with COVID-19 pneumonia can develop myocardial injury or even fulminant myocarditis [44, 45]. Echo findings in myocarditis include chamber size alterations, increasing wall thickness, global or regional ventricular dysfunction, and diastolic dysfunction [46]. In pericarditis, a pericardial effusion can be detected [47]. It can mimic ischemic cardiomyopathy [48]. In fulminant myocarditis, a nondilated, thickened and hypocontractile left ventricle is seen, as the inflammatory response results in interstitial edema and loss of ventricular contractility (video 4-myocardial edema of the left ventricle (LV) in myocarditis) [49].
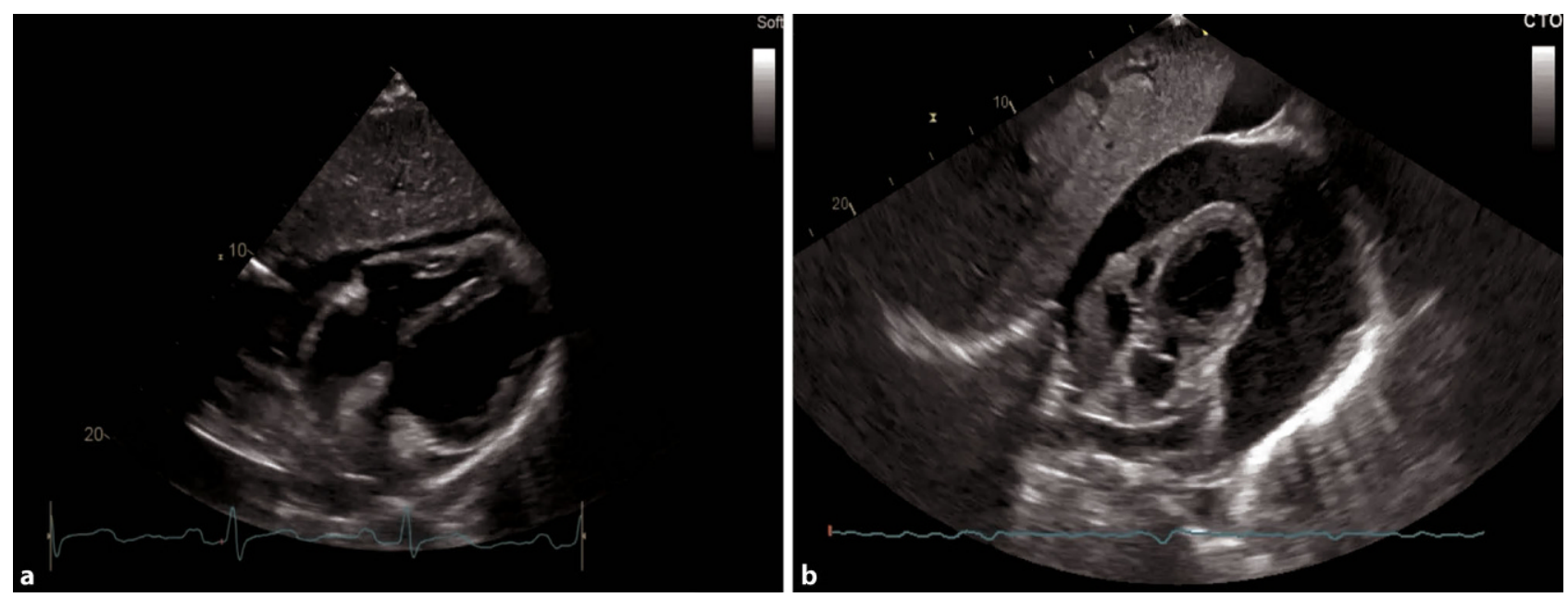

Fig. 14 Pericardial effusion in a subcostal 4-ChV. a Small-medium pericardial effusion. $\mathbf{b}$ Large pericardial effusion 
For detecting myocarditis in an intensive care setting, a subcostal $4-\mathrm{ChV}$ should initially be chosen (Fig. 11). In a subcostal approach, pericardial effusion can also be visualized (Fig. 14). An assessment of the global, left and right ventricular function is also possible. An alternative view to detect pericardial effusion and reduced global ventricular function is the $4-\mathrm{ChV}$. Regional wall motion abnormalities (WMA) should be assessed in a comprehensive examination [43].

In our experience, hyperdynamic right ventricular function (RVF) and left ventricular function (LVF) are frequently seen in combination with mildly elevated systolic pulmonary artery pressures (sPAP), remaining after intensive care treatment in patients, with or without prior cardiovascular disease such as hypertension; however, a normalization can be seen after a few months in a majority of patients.

In strain imaging, there can be regional and global changes, which persist over the course of several months. The implications for treatment over a longer period and the clinical relevance in the follow-up have not yet been established [50].

\section{Pulmonary embolism}

Hypercoagulopathy is described in COVID-19 patients, and pulmonary embolism is a life-threatening complication thereof. Therefore, it is crucial to recognize the echocardiographic features of a hemodynamically relevant pulmonary embolism, to be able to initiate treatment $[28,38,51]$.

In an acute, hemodynamically relevant pulmonary embolism (PE), the main features in echocardiography are a dilated right ventricle (RV), with the basal diameter $>41 \mathrm{~mm}$ (as seen in Fig. 15a), reduced RVF, especially at the basal parts, S' $<9.5 \mathrm{~cm} / \mathrm{s}$, tricuspid annular plane systolic excursion (TAPSE) $<17 \mathrm{~mm}$, sometimes with a hyperdynamic apical region (McConnell sign). The sPAP is normal, low or mildly elevated [52]. A 60/60 sign which describes an sPAP of more than
$30 \mathrm{~mm} \mathrm{Hg}$ but less than $60 \mathrm{mmHg}$, and a right ventricular outflow tract acceleration time of less than $60 \mathrm{~ms}$, can be present [53]. The inferior vena cava (IVC) can be dilated with reduced, or even without, respiratory collapsibility. In a parasternal short axis view, a D-shape of the left ventricle can be visualized, and severe tricuspid regurgitation (TR) can be present (Fig. 15b; [54, 55]). None of these echocardiographic findings are specific for acute PE, but in the setting of COVID-19, in particular in an intensive care setting, it is reported that up to one third of patients do develop PE [56].

On the ICU, the optimal view to visualize the right heart is a subcostal $4-\mathrm{ChV}$, permitting visual assessment of RVF and size. Color Doppler of the region of the tricuspid valve can provide information as to whether severe TR is present (Fig. 15b). Additional views, especially in follow up examinations, include apical and parasternal views, as seen in Figs. 12 and 13. SPAP should be measured with continuous wave Doppler across the tricuspid valve, according to current guidelines [57].

\section{Acute coronary syndromes and heart failure}

Acute heart failure can be the primary symptom of COVID-19 infection with 50\% of COVID-19 patients having no prior cardiovascular diseases [44]. Severe inflammation increases the risk of acute myocardial infarction [58].

Detecting regional WMA in ICU patients can be challenging. Several views should be obtained. In an apical $4-\mathrm{ChV}$, the apical regions can be visualized, and in the PLAX, the posterolateral and the anteroseptal wall of the LV can be seen. For evaluation of RV dysfunction and larger LV infarcts, a subcostal 4-ChV is optimal $[43,57]$. For an evaluation of regional WMA and RVF, a comprehensive transthoracic examination is required [43].
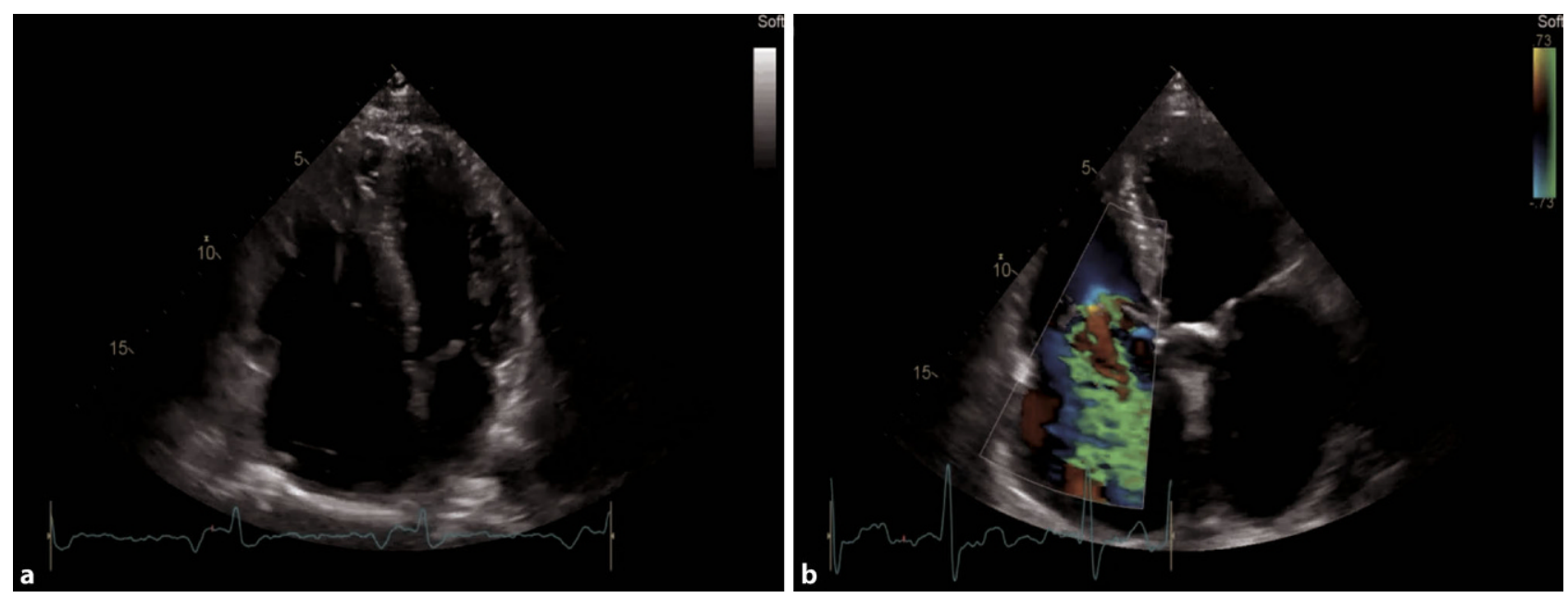

Fig. 15 Pathologies of the right heart in an apical 4-ChV. a RV dilatation due to myocarditis. b Severe tricuspid regurgitation 


\section{Conclusion}

In COVID-19, ultrasound plays an important role in diagnosing pneumonia, corresponding complications, including ACS and bacterial superinfections, and cardiac conditions [23, 44, 45].

Lung ultrasound has the potential to be useful in diagnosing COVID-19 pneumonia and complications such as bacterial superinfection or pneumothorax [24]. The need for other imaging modalities can be reduced, and radiation can be avoided [59]. Lung ultrasound can aid treatment of patients in a critical condition and in time help identify complete regression of the disease $[60,61]$.

We recommend following a standard 12-zone protocol for LUS in a COVID-19 setting, whenever possible, with the aim of identifying changes over time, using the provided measurements and tools for quantification. In detecting a pneumothorax, a POCUS approach should be chosen [23, 40]. Automated measurements for reverberation artifacts can be used and might detect subvisible biomarkers helping to differentiate the cause of reverberation artifacts and might be useful in the future $[62,63]$.

Echocardiography in a point of care approach is an easy and accessible tool to optimally identify cardiac complications in COVID-19, such as tamponade, pericardial effusion and severely reduced LV and RV function $[44,45]$. In a comprehensive approach, we recommend following the internationally established protocols and include strain analysis to monitor patients after COVID-19 to identify persistent changes in echocardiography such as elevation of SPAP, regional WMA, reduction in global longitudinal strain (GLS) of the LV, RV dilatation and diastolic dysfunction [50, 57, 64].

Overall, echocardiography and lung ultrasound combined can be of tremendous help in identifying life-threatening conditions and can be used in the management of patients in intensive care units. It is also a valuable tool for in follow-up care in the context of the pandemic $[50,65]$. Especially the topic of strain imaging with the first evaluation on the ICU of left and right ventricular strain as well as in the follow-up will be relevant in the future as a reduced GLS and reduced RV strain seem to reflect a marker of poor prognosis [66, 67].

Funding Open access funding provided by Medical University of Vienna.

Conflict of interest M. Altersberger, M. Schneider, M. Schiller, C. Binder-Rodriguez, M. Genger, M. Khafaga, T. Binder and $H$. Prosch declare that they have no competing interests.

Open Access This article is licensed under a Creative Commons Attribution 4.0 International License, which permits use, sharing, adaptation, distribution and reproduction in any medium or format, as long as you give appropriate credit to the original author(s) and the source, provide a link to the Creative Commons licence, and indicate if changes were made. The images or other third party material in this article are included in the article's Creative Commons licence, unless indicated otherwise in a credit line to the material. If material is not included in the article's Creative Commons licence and your intended use is not permitted by statutory regulation or exceeds the permitted use, you will need to obtain permission directly from the copyright holder. To view a copy of this licence, visit http://creativecommons.org/licenses/by/4.0/.

\section{References}

1. Zhu N, Zhang D, Wang W, Li X, Yang B, Song J, et al. A novel coronavirus from patients with pneumonia in China, 2019. NEngl J Med. 2020;382(8):727-33.

2. CoronaviridaeStudy Group of the International Committee on Taxonomy of Viruses. The species Severe acute respiratory syndrome-related coronavirus: classifying $2019-\mathrm{nCoV}$ and naming it SARS-CoV-2. Nat Microbiol. 2020;5:536-44. https://doi.org/10.1038/s41564-020-0695-z.

3. Schneider M, Altersberger M, Binder C, Hengstenberg C, Binder T. The COVID-19 burden for health care professionals: Results of a global survey. Eur J Intern Med. 2021;83:96-8. https://doi.org/10.1016/j.ejim.2020.11.011. Epub2020 Nov 12. PMID: 33221130; PMCID: PMC7659805.

4. Krantz SG, Rao ASRS. Level of under-reporting including under-diagnosis before the first peak of COVID-19 in various countries: preliminary retrospective results based on wavelets and deterministic modeling. Infect Control Hosp Epidemiol. 2020;41(7):857-9.

5. Wei WE, Li Z, Chiew CJ, Yong SE, Toh MP, Lee VJ. Presymptomatic transmission of SARS-CoV-2-Singapore, January 23-March 16, 2020. MMWR Morb Mortal Wkly Rep. 2020;69(14):411-5.

6. Day M. Covid-19: four fifths of cases are asymptomatic, China figures indicate. BMJ. 2020;369:m1375.

7. Rothe C, Schunk M, Sothmann P, Bretzel G, Froeschl G, Wallrauch C, et al. Transmission of 2019-NCOV infection from an asymptomatic contact in Germany. N Engl J Med. 2020;382(10):970-1.

8. Bai Y, Yao L, Wei T, Tian F, Jin DY, Chen L, et al. Presumed asymptomatic carrier transmission of COVID-19. JAMA. 2020;323(14):1406.

9. Kimball A, Hatfield KM, Arons M, James A, Taylor J, Spicer K, et al. Asymptomatic and Presymptomatic SARS-coV-2 infections in residents of a long-term care skilled nursing facility-King county, Washington, march 2020. MMWR Morb Mortal Wkly Rep. 2020;69(13):377-81.

10. Tang YW, Schmitz JE, Persing DH, Stratton CW. Laboratory Diagnosis of COVID-19: Current Issues and Challenges. J Clin Microbiol. 2020;58(6):e00512-20. https://doi. org/10.1128/JCM.00512-20. PMID: 32245835; PMCID: PMC7269383.

11. S. K, U. J, T. W, S. W-C, G. M, C. K. Recommendations for critically ill patients with COVID-19. Medizinische Klin - Intensivmed und Notfallmedizin [Internet]. 2020; Available from: http://www.embase.com/search/results? subaction=viewrecord\&from=export\&id=L2004450506 \%0Ahttp://dx.doi.org/10.1007/s00063-020-00674-3.

12. Gautier JF, Ravussin Y. A New Symptom of COVID-19: Loss of Taste and Smell. Obesity (Silver Spring). 2020;28(5):848. https://doi.org/10.1002/oby.22809. Epub 2020 Apr 1. PMID: 32237199; PMCID: PMC7228286.

13. KnightSR, Ho A, Pius R, Buchan I, Carson G, DrakeTM, Dunning J, Fairfield CJ, Gamble C, Green CA, Gupta R, Halpin S, Hardwick HE, Holden KA, Horby PW, Jackson C, Mclean KA, Merson L, Nguyen-Van-Tam JS, Norman L, Noursadeghi M, Olliaro PL, Pritchard MG, Russell CD, Shaw CA, Sheikh A, 
Solomon T, Sudlow C, Swann OV, Turtle LC, Openshaw PJ, BaillieJK, SempleMG, DochertyAB,HarrisonEM;ISARIC4C investigators. Risk stratification of patients admitted to hospital with covid-19 using the ISARICWHOClinical Characterisation Protocol: development and validation of the 4C Mortality Score. BMJ. 2020;370:m3339. https://doi. org/10.1136/bmj.m3339. Erratum in: BMJ. 2020 Nov 13;371:m4334. PMID: 32907855; PMCID: PMC7116472.

14. Yang X, Yu Y, Xu J, Shu H, Xia J, Liu H, et al. Clinical course and outcomes of critically ill patients with SARSCoV-2 pneumonia in Wuhan, China: a single-centered, retrospective, observational study. Lancet Respir Med. 2020. https://doi.org/10.1016/S2213-2600(20)30079-5.

15. Noppen M, De Keukeleire T. Pneumothorax. Respiration 2008;76:121-7.https://doi.org/10.1159/000135932.

16. Hussain A, Noorani A, Deshpande R, John L, Baghai M, Wendler $\mathrm{O}$, et al. Management of pneumothorax in mechanically ventilated COVID-19 patients: early experience. Interact Cardiovasc Thorac Surg. 2020;31:540-3. https:// doi.org/10.1093/icvts/ivaa129.

17. Xiao AT, Tong YX, Zhang S. False negative of RT-PCR and prolonged nucleic acid conversion in COVID-19: Rather than recurrence. J Med Virol. 2020;92(10):1755-6. https:// doi.org/10.1002/jmv.25855. Epub 2020 Jul 11. PMID: 32270882; PMCID: PMC7262304.

18. Afzal A. Molecular diagnostic technologies for COVID-19: Limitations and challenges. J Adv Res. 2020;26:149-59. https://doi.org/10.1016/j.jare.2020.08.002. Epub 2020 Aug 6. PMID: 32837738; PMCID: PMC7406419.

19. Rubin GD, Ryerson CJ, Haramati LB, Sverzellati N, Kanne JP Raoof S, Schluger NW, Volpi A, Yim J-J, Martin IBK, Anderson DJ, Kong C, Altes T, Bush A, Desai SR, Goldin O, Goo JM, Humbert M, Inoue Y, Kauczor H-U, Luo F, Mazzone PJ, Prokop M, Remy-Jardin M, Richeldi L, SchaeferProkop CM, Tomiyama N, Wells AU, Leung AN. The Role of Chest Imaging in Patient Management during the COVID19 Pandemic: A Multinational Consensus Statement from the Fleischner Society. Radiology. 2020;296(1):172-80.

20. Revel MP, Parkar AP, Prosch H, Silva M, Sverzellati N, Gleeson F, Brady A; European Society of Radiology (ESR) and the European Society of Thoracic Imaging (ESTI). COVID-19 patients and the radiology department - advice from the European Society of Radiology (ESR) and the European Society of Thoracic Imaging (ESTI). Eur Radiol. 2020;30(9):4903-9. https://doi.org/10.1007/s00330-02006865-y. Epub 2020 Apr 20. PMID: 32314058; PMCID: PMC7170031.

21. Jajodia A, Ebner L, Heidinger B, Chaturvedi A, Prosch H. Imaging in corona virus disease 2019 (COVID-19) - A scoping review. Eur J Radiol Open. 2020;7:100237. https://doi. org/10.1016/j.ejro.2020.100237.

22. World Health Organization. Antigen-detection in the diagnosis of SARS-CoV-2 infection using rapid immunoassays: interim guidance, 11 September 2020. World Health Organization. https://apps.who.int/iris/handle/10665/334253 (2020). License: CCBY-NC-SA3.0 IGO.

23. Gargani L, Soliman-Aboumarie H, Volpicelli G, Corradi F, Pastore MC, Cameli M. Why, when, and how to use lung ultrasound during the COVID-19 pandemic: enthusiasm and caution. Eur Heart J Cardiovasc Imaging. 2020;21 (9):941-8. https://doi.org/10.1093/ehjci/jeaal63.

24. Volpicelli G, Lamorte A, Villén T. What's new in lung ultrasound during the COVID-19 pandemic. Intensive Care Med. 2020; https://doi.org/10.1007/s00134-020-06048-9.

25. Smith MJ, Hayward SA, Innes SM, Miller ASC. Point-of-care lung ultrasound in patients with COVID-19-a narrative review. Anaesthesia. 2020;75(8):1096-104.https://doi.org/ 10.1111/anae.15082. Epub 2020 Apr 28. PMID: 32275766; PMCID: PMC7262296.

26. PengQY,WangXT,ZhangLN. Findings oflungultrasonography of novel corona virus pneumonia during the 2019-2020 epidemic. Intensive Care Med. 2020;46(5):849-50.

27. Soldati G, Smargiassi A, Inchingolo R, Buonsenso D, Perrone T, Briganti DF, Perlini S, Torri E, Mariani A, Mossolani EE, Tursi F, Mento F, Demi L. Proposal for International Standardization of the Use of Lung Ultrasound for Patients With COVID-19: A Simple, Quantitative, Reproducible Method. J Ultrasound Med. 2020;39(7):1413-9. https://doi.org/10.1002/jum.15285. Epub 2020 Apr 13. PMID: 32227492; PMCID: PMC7228287.

28. Soldati G, Smargiassi A, Inchingolo R, Buonsenso D, Perrone $\mathrm{T}$, Briganti $\mathrm{DF}$, et al. Is there a role for lung ultrasound during the COVID-19 pandemic? J Ultrasound Med. 2020;39(7):1459-62.

29. Johri AM, Galen B, James N, Lanspa M, Mulvagh S, Thamman R, et al. ASE statement on Point-of-Care Ultrasound ( POCUS ) during the 2019 novel coronavirus pandemic. 2020. pp. 1-8.

30. Aziz R, Kaminstein D. Use of lung ultrasound for COVID19 in the intensive care unit. BJA Educ. 2020;20(12):400-3. https://doi.org/10.1016/j.bjae.2020.09.001.

31. Gehmacher O, Mathis G, Kopf A, Scheier M. Ultrasound imaging of pneumonia. Ultrasound Med Biol. 1995;21(9):1119-22.

32. Buda N, Kosiak W, Wełnicki M, Skoczylas A, Olszewski R, Piotrkowski J, et al. Recommendations for lung ultrasound in internal medicine. Diagnostics. 2020;10(8):597.

33. Lichtenstein D. Lung ultrasound in the critically ill. Curr Opin Crit Care. 2014;20(3):315-22.

34. LichterY, TopilskyY, TaiebP, BanaiA, HochstadtA, MerdlerI, et al. Lung ultrasound predicts clinical course and outcomes in COVID-19 patients. Intensive Care Med. 2020;46(10):1873-83.

35. Mayo PH, Copetti R, Feller-Kopman D, Mathis G, Maury E, Mongodi S, et al. Thoracic ultrasonography: a narrative review. Intensive Care Med. 2019;45(9):1200-11.

36. Abdel Kader M, Osman NMM. Implementation of chest ultrasound with color Doppler in diagnosis of pneumonia in adults. Egypt J Radiol Nucl Med. 2016;47(3):771-81. https://doi.org/10.1016/j.ejrnm.2016.05.015.

37. Hsu WH, Yu YH, Tu CY, Hsu JY, Chen CY, Chen CL, et al. Color Doppler US pulmonary artery vessel signal: a sign for predicting the benign lesions. Ultrasound Med Biol. 2007;33(3):379-88.

38. Tang N, Li D, Wang X, Sun Z. Abnormal coagulation parameters are associated with poor prognosis in patients with novel coronavirus pneumonia. J Thromb Haemost. 2020;18(4):844-7.

39. Soni N, Franco R, Velez M, Schnobrich D, Dancel R, Restrepo M, Mayo PH. Ultrasound in the diagnosis and management of pleural effusions. J Hosp Med. 2015;10(12):811-6.

40. Volpicelli G, Elbarbary M, Blaivas M, Lichtenstein DA, Mathis G, Kirkpatrick AW, et al. International evidencebased recommendations for point-of-carelungultrasound. Intensive Care Med. 2012;38(4):577-91.

41. Zantah M, Dominguez Castillo E, Townsend R, et al. Pneumothorax in COVID-19 disease- incidence and clinical characteristics. Respir Res. 2020;21:236. https://doi.org/ 10.1186/s12931-020-01504-y.

42. Lichtenstein DA, Lascols N, Prin S, Mezière G. The "lung pulse": an early ultrasound sign of complete atelectasis. Intensive Care Med. 2003;29(12):2187-92. 
43. Mitchell C, Rahko PS, Blauwet LA, Canaday B, Finstuen JA, Foster MC, et al. Guidelines for performing a comprehensive transthoracic echocardiographic examination in adults: recommendations from the American Society of Echocardiography. J Am Soc Echocardiogr. 2019;32(1):1-64. https://doi.org/10.1016/j.echo.2018.06. 004 .

44. Long B, Brady WJ, Koyfman A, Gottlieb M. Since January 2020 Elsevier has created a COVID-19 resource centre with free information in English and Mandarin on the novel coronavirus COVID-19. The COVID-19 resource centre is hosted on Elsevier Connect , the company's public news and information. 2020.

45. Jaffe AS, Cleland JGF, Katus HA. Myocardial injury in severe COVID-19infection. Eur Heart J. 2020;41(22):2080-2.

46. Pinamonti B, Alberti E, Cigalotto A, Dreas L, Salvi A, Silvestri F, et al. Echocardiographic findings in myocarditis. Am J Cardiol. 1988;62(4):285-91.

47. Adler Y, Charron P, Imazio M, Badano L, Barón-Esquivias G, Bogaert J, et al. 2015 ESC Guidelines for the diagnosis and management of pericardial diseases. Eur Heart J. 2015;73(11):1028-91.

48. Caforio ALP, Pankuweit S, Arbustini E, Basso C, GimenoBlanes J, Felix SB, et al. Current state of knowledge on aetiology, diagnosis, management, and therapy of myocarditis: a position statement of the European Society of Cardiology Working Group on Myocardial and PericardialDiseases. Eur Heart J. 2013;34(33):2636-48.

49. Felker GM, Boehmer JP, Hruban RH, Hutchins GM, Kasper EK, Baughman KL, etal. Echocardiographic findings in fulminant and acute myocarditis. J Am Coll Cardiol. 2000;36(1):227-32.

50. Stöbe S, Richter S, Seige M, Stehr S, Laufs U, Hagendorff A. Echocardiographic characteristics of patients with SARSCoV-2 infection. Clin Res Cardiol. 2020;109(12):1549-66.

51. Guzik TJ, Mohiddin SA, Dimarco A, Patel V, Savvatis K, Marelli-Berg FM, et al. COVID-19 and the cardiovascular system: implications for risk assessment, diagnosis, and treatment options. Cardiovasc Res. 2020;116(10):1666-87.

52. Konstantinides SV, Meyer G, Bueno H, Galié N, Gibbs JSR, Ageno W, et al. 2019 ESC Guidelines for the diagnosis and management of acute pulmonary embolism developed in collaboration with the European respiratory society (ERS). Eur Heart J. 2020;41(4):543-603.

53. Kurzyna M, Torbicki A, Pruszczyk P, Burakowska B, Fijałkowska A, Kober J, et al. Disturbed right ventricular ejection pattern as a new Doppler echocardiographic sign of acute pulmonary embolism. Am J Cardiol. 2002;90(5):507-11

54. Kurnicka K, Lichodziejewska B, Goliszek S, DzikowskaDiduch O, Zdończyk O, Kozłowska M, et al. Echocardiographic pattern of acute pulmonary embolism: analysis of 511 consecutive patients. J Am Soc Echocardiogr. 2016;29(9):907-13.

55. Weekes AJ, Oh L, Thacker G, Johnson AK, Runyon M, Rose G, et al. Interobserver and intraobserver agreement on qualitative assessments of right ventricular dysfunction with echocardiography in patients with pulmonary embolism. J Ultrasound Med. 2016;35(10):2113-20.

56. Sakr Y, Giovini M, Leone M, Pizzilli G, Kortgen A, Bauer M, Tonetti T, Duclos G, Zieleskiewicz L, Buschbeck S, Ranieri VM, Antonucci E. Pulmonary embolism in patients with coronavirus disease-2019 (COVID-19) pneumonia: a narrative review. Ann Intensive Care. 2020;10:124. https:// doi.org/10.1186/s13613-020-00741-0. PMID: 32953201; PMCID: PMC7492788.
57. Lang RM, Badano LP, Mor-Avi V, Afilalo J, Armstrong A, Ernande L, Flachskampf FA, Foster E, Goldstein SA, Kuznetsova T, Lancellotti P, Muraru D, Picard MH, Rietzschel ER, Rudski L, Spencer KT, Tsang W, Voigt JU. Recommendations for cardiac chamber quantification by echocardiography in adults: an update from the American Society of Echocardiography and the European Association of Cardiovascular Imaging. J Am Soc Echocardiogr. 2015;28(1):1-39.e14. https://doi.org/10.1016/j.echo.2014. 10.003. PMID: 25559473.

58. Kwong JC, Schwartz KL, Campitelli MA, Chung H, Crowcroft NS, Karnauchow T, et al. Acute myocardial infarction after laboratory-confirmed influenza infection. NEngl J Med. 2018;378(4):345-53.

59. Moore S, Gardiner E. Point of care and intensive care lung ultrasound: a reference guide for practitioners during COVID-19. Radiography. 2020;26(4):e297-e302.

60 . Tung-Chen Y. Lung ultrasound in the monitoring of COVID19 infection. Clin Med (Lond). 2020;20(4):e62-5. https:// doi.org/10.7861/clinmed.2020-0123. Epub 2020 May 12. PMID: 32398268; PMCID: PMC7385798.

61. McElyea C, Do C, Killu K. Lung ultrasound artifacts in COVID-19 patients [published online ahead of print, 2020 Aug 25]. J Ultrasound. 2020. https://doi.org/10.1007/ s40477-020-00526-y.

62. Born J, Beymer D, Rajan D, et al. On the role of artificial intelligence in medical imaging of COVID-19. Patterns. 2021;2(6):100269. https://doi.org/10.1016/j.patter.2021. 100269.

63. Arntfield R, VanBerlo B, Alaifan T, Phelps N, White M, Chaudhary R, et al. Development of a convolutional neural network to differentiate among the etiology of similar appearing pathological B lines on lung ultrasound: a deep learning study. BMJOpen. 2021;11(3):e45120.

64. Nagueh SF, Smiseth OA, Appleton CP, Byrd BF 3rd, Dokainish H, Edvardsen T, Flachskampf FA, Gillebert TC, Klein AL, Lancellotti P, Marino P, Oh JK, Popescu BA, Waggoner AD. Recommendations for the Evaluation of Left Ventricular Diastolic Function by Echocardiography: An Update from the American Society of Echocardiography and the European Association of Cardiovascular Imaging. J Am Soc Echocardiogr. 2016;29(4):277-314. https://doi.org/10.1016/j.echo. 2016.01.011. PMID: 27037982.

65. Dweck MR, Bularga A, Hahn RT, Bing R, Lee KK, Chapman AR, White A, Di Salvo G, Sade LE, Pearce K, Newby DE, Popescu BA, Donal E, Cosyns B, Edvardsen T, Mills NL, Haugaa K. Global Evaluation of Echocardiography in Patients with COVID-19. European Heart Journal-Cardiovascular Imaging. 2020;21(9):949-58. https://doi.org/10.1093/ ehjci/jeaal78.

66. Park J, Kim Y, Pereira J, Hennessey KC, Faridi KF, McNamara RL, Velazquez EJ, Hur DJ, Sugeng L, Agarwal V. Understanding the role of left and right ventricular strain assessment in patients hospitalized with COVID-19. Am HeartJPlus. 2021;6:100018. https:// doi.org/10.1016/j.ahjo. 2021.100018. Epub 2021 Jun 1. PMID: 34095889; PMCID: PMC8168299.

67. Shmueli H, Shah M, Ebinger JE, Nguyen LC, Chernomordik F, Flint N, Botting P, Siegel RJ. Left ventricular global longitudinal strain in identifying subclinical myocardial dysfunction among patients hospitalized with COVID19. Int J Cardiol Heart Vasc. 2021;32:100719. https://doi. org/10.1016/j.ijcha.2021.100719. Epub 2021 Jan 25. PMID: 33521240; PMCID: PMC7830223.

Publisher's Note Springer Nature remains neutral with regard to jurisdictional claims in published maps and institutional affiliations. 